\title{
Mono- and combination drug therapies in hospitalized patients with bipolar depression. Data from the European drug surveillance program AMSP
}

\author{
Anne Haeberle ${ }^{1}$, Waldemar Greil ${ }^{1,2^{*}}$, Stefan Russmann ${ }^{3}$ and Renate Grohmann ${ }^{1}$
}

\begin{abstract}
Background: For the pharmacological treatment of bipolar depression several guidelines exist. It is largely unknown, to what extent the prescriptions in daily clinical routine correspond to these evidence based recommendations and which combinations of psychotropic drugs are frequently used.
\end{abstract}

Methods: The prescriptions of psychotropic drugs were investigated of all in-patients with bipolar depression ( $n=2246$; time period 1994-2009) from hospitals participating in the drug surveillance program AMSP. For the drug use in 2010, 221 cases were analysed additionally.

Results: From 1994 to 2009, 85\% of all patients received more than one class of psychotropic substances: 74\% received antidepressants in combination therapy, 55\% antipsychotics, $48 \%$ anticonvulsants and 33\% lithium. When given in combination, lithium is the most often prescribed substance for bipolar depression (33\%), followed by valproic acid (23\%), mirtazapine and venlafaxine (16\% each), quetiapine (15\%), lamotrigine (14\%) and olanzapine (13\%). Both, lithium and valproic acid are often combined with selective serotonin reuptake inhibitors (SSRI), but also with mirtazapine und venlafaxine. Combinations of more than one antidepressant occur quite often, whereby combinations with bupropion, paroxetine, fluoxetine or fluvoxamine are very rare. In 2010, quetiapine (alone and combined) was the most frequently prescribed drug (39\%); aripiprazole was administered in 10\%.

Conclusion: Combinations of antidepressants (SSRI, mirtazapine, venlafaxine) with mood stabilizers (lithium, valproic acid, lamotrigine) and / or atypical antipsychotics (quetiapine, olanzapine) are common. Of most of those combinations the efficacy has not been studied. The use of aripiprazole and the concomitant use of two or three antidepressants contrast the guidelines.

Keywords: AMSP, Bipolar depression, Bipolar disorder, Combination therapy, Drug surveillance, Guidelines, Pharmacotherapy, Prescription, Psychotropic drugs, Antidepressants

\section{Background}

For the treatment of bipolar depression a variety of partly controversial options exist. Several up to date guidelines provide clinicians with a framework of evidence based pharmacological treatments of bipolar depression [1-6].

\footnotetext{
* Correspondence: waldemar.greil@med.uni-muenchen.de

'Department of Psychiatry, Ludwig Maximilian University, Munich, Germany,

Nussbaumstr. 7, Munich 80336, Germany

${ }^{2}$ Sanatorium Kilchberg, Alte Landstrasse 70, Kilchberg-Zurich 8802

Switzerland

Full list of author information is available at the end of the article
}

The present study shows the prescriptions of psychopharmacological substances for bipolar depression in daily clinical routine. The data from a large European multicenter study (AMSP) $[7,8]$ allow a direct comparison between clinical routine and recommendations of the guidelines.

Previous analysis of these data have shown several important prescribing trends in the treatment of bipolar depression from 1994 until 2009: Antidepressants are prescribed in almost $80 \%$ of all in-patients, thus being by far the most important class of psychotropic drugs 
prescribed for bipolar depression; antipsychotics in about $60 \%$ with increasing trend, especially for quetiapine; anticonvulsants in about 50\%, mostly valproic acid and lamotrigine and lithium in about 35\% with a decreasing trend. Furthermore, a pronounced increase of polypharmacy was found [9].

For the first time, the present article investigates specifically the most frequently administered combinations of psychotropic substances and focuses on the use of single antidepressant drugs over the time of 15 years in hospitalized patients with bipolar depression.

\section{Method}

\section{Patients}

All in-patients with a diagnosis of bipolar depression hospitalized in the participating hospitals of the AMSP project were selected $(n=2246$; time period 1994-2009). For the years 2001 - 2009 patients with the diagnoses F 31.3 31.5 according to ICD 10 were selected, for the years 1994 - 2000 patients with the corresponding diagnosis in ICD 9 (manic-depressive psychosis, circular type, currently depressed) were included. A detailed description of the patient population can be found in Greil et al. 2012 [9]. For the present analysis 15 patients with missing personal data not included in the previous analysis were added to the population. For the special calculation of drug use in 2010 additional 221 cases were analysed.

\section{Data collection}

The present data were taken from the large data pool of the AMSP program (Arzneimittelsicherheit in der Psychiatrie) [7]. This drug safety project was started in 1993 by the Psychiatric University Hospital Munich and serves to continuously record prescriptions of psychotropic drugs and their adverse side effects of in-patients of various hospitals in Germany, Switzerland and Austria (and temporarily also Hungary and Belgium). In 2009,
51 hospitals participated in the project. The data on prescription rates were gathered twice a year as follows: At two index dates per year each participating hospital / ward recorded for each patient hospitalized at that day age, sex, psychiatric diagnosis (ICD 9 and 10, respectively) and daily dosage of all drugs (psychotropic and non-psychotropic). These data were subsequently sent to the Psychiatric University Hospital Munich, where they were collected in an overall database.

\section{Data analysis}

To statistically analyse the rates of psychopharmacological prescriptions, the percentage of patients per year was calculated, which received a particular agent. The number of patients receiving a particular agent in one year was divided by the total number of patients in this year = prescription rate, i.e. percentage of patients receiving the agent per year. Although the data were collected twice per calendar year, an average prescription rate was calculated using the data of one calendar year. Hence, we phrase "\% of patients" referring to virtual single patients. For the analyses, the period 1994-2009 was segmented into four equal time periods due to low number of patients with single drugs.

The ethics committee of the Ludwig Maximilian University of Munich, the location of the AMSP main data center, had approved the analysis of the AMSP data with a waver of authorization. The permission to use the special data set of bipolar depression was given by the publication commission consisting of the presidents of the AMSP associations in Germany, Austria and Switzerland.

\section{Results}

Frequency of prescriptions of drug classes in combination therapy

Table 1 shows that within the period from 1994 to 2009, $85 \%$ of all hospitalized patients treated for bipolar

Table 1 Frequency of prescriptions in mono- and combination therapy for classes of psychotropic substances

\begin{tabular}{|c|c|c|c|c|c|c|c|c|c|c|c|}
\hline & & \multicolumn{2}{|c|}{$1994-1997$} & \multicolumn{2}{|c|}{$1998-2001$} & \multicolumn{2}{|c|}{$2002-2005$} & \multicolumn{2}{|c|}{$2006-2009$} & \multicolumn{2}{|c|}{ Overall } \\
\hline & & $\mathbf{N}$ & $\%$ & $\mathbf{N}$ & $\%$ & $\mathbf{N}$ & $\%$ & $\mathbf{N}$ & $\%$ & $\mathbf{N}$ & $\%$ \\
\hline \multicolumn{2}{|c|}{ Number of patients } & 248 & & 454 & & 711 & & 832 & & 2246 & \\
\hline \multicolumn{2}{|c|}{ Number of patients monotherapy } & 53 & 21.4 & 99 & 21.8 & 85 & 12.0 & 97 & 11.7 & 334 & 14.9 \\
\hline \multicolumn{2}{|c|}{ Number of patients combination therapy } & 195 & 78.6 & 355 & 78.2 & 626 & 88.0 & 735 & 88.3 & 1912 & 85.1 \\
\hline \multirow[t]{2}{*}{ Antidepressants } & monotherapy & 33 & 13.3 & 54 & 11.9 & 41 & 5.8 & 43 & 5.2 & 171 & 7.6 \\
\hline & combination therapy & 172 & 69.4 & 317 & 69.8 & 531 & 74.7 & 634 & 76.2 & 1655 & 73.7 \\
\hline \multirow[t]{2}{*}{ Antipsychotics } & monotherapy & 8 & 3.2 & 16 & 3.5 & 16 & 2.3 & 30 & 3.6 & 70 & 3.1 \\
\hline & combination therapy & 97 & 39.1 & 194 & 42.7 & 418 & 58.8 & 534 & 64.2 & 1244 & 55.4 \\
\hline \multirow[t]{2}{*}{ Anticonvulsants } & monotherapy & 6 & 2.4 & 16 & 3.5 & 15 & 2.1 & 14 & 1.7 & 51 & 2.3 \\
\hline & combination therapy & 65 & 26.2 & 177 & 39.0 & 402 & 56.5 & 425 & 51.1 & 1069 & 47.6 \\
\hline \multirow[t]{2}{*}{ Lithium } & monotherapy & 6 & 2.4 & 13 & 2.9 & 13 & 1.8 & 10 & 1.2 & 42 & 1.9 \\
\hline & combination therapy & 105 & 42.3 & 152 & 33.5 & 204 & 28.7 & 275 & 33.1 & 736 & 32.8 \\
\hline
\end{tabular}


depression received more than one class of psychotropic substances: $74 \%$ of all patients received antidepressants, $55 \%$ antipsychotics, $48 \%$ anticonvulsants and 33\% lithium in combination therapy, i.e. in combination with other drugs of these four drug classes.

Monotherapy had a low prevalence (about 15\% of the patients) and shows a decreasing trend. A remarkable decrease is seen for antidepressant monotherapy, from $13 \%$ to $5 \%$ in the time period from 1994 to 1997 as compared to the last period from 2006 to 2009. Hereby, monotherapy is defined as the use of either antidepressants or antipsychotics or anticonvulsants or lithium, but additional use of hypnotics and tranquilizers or the use of more than one drug within the respective class being allowed (see also [9]).

\section{Psychotropic substances in mono- and combination therapy}

Table 2 shows the single psychotropic substances prescribed most frequently in mono- as well as in combination therapy. When given in combination, lithium is the most often prescribed substance for bipolar depression (33\%), followed by valproic acid (23\%), mirtazapine and venlafaxine (16\% each), quetiapine (15\%), lamotrigine (14\%) and olanzapine (13\%). The group of SSRI is frequently included in combination therapy $(26 \%$ of the patients), especially escitalopram (9\%) and citalopram (8\%). Note that paroxetine and fluoxetine are prescribed rarely and fluvoxamine as well as bupropion are given only exceptionally. Interestingly, quetiapine and lamotrigine were often administered as combination therapy, but very rarely as monotherapy $(0.6 \%$ and $0.3 \%$, respectively).

The analysis of the prescription data from 2010 (patients with bipolar depression, $\mathrm{n}=221$ ) shows the following results for the most often used single drugs: Quetiapine (alone and in combination) is prescribed in $38.9 \%$ of the patients, followed by valproic acid (33.5\%), lithium (26.7\%), escitalopram (19.5\%), lamotrigine (18.6\%), venlafaxine (17.7\%) and mirtazapine (14.5\%).

Table 2 Frequency of prescriptions of single psychotropic substances

\begin{tabular}{|c|c|c|c|c|c|}
\hline$\%$ & $1994-1997$ & $1998-2001$ & $2002-2005$ & $2006-2009$ & Overall \\
\hline $\mathrm{N}$ & 248 & 454 & 711 & 832 & 2246 \\
\hline Lithium & $2.4+42.3$ & $2.9+33.5$ & $1.8+\mathbf{2 8 . 7}$ & $1.2+33.1$ & $1.9+32.8$ \\
\hline SSRI overall & $2.4+15.3$ & $3.5+\mathbf{2 2 . 4}$ & $2.4+29$ & $2.0+\mathbf{2 8 . 6}$ & $2.5+\mathbf{2 6 . 0}$ \\
\hline Valproic acid & $0.4+\mathbf{4 . 8}$ & $1.8+\mathbf{1 9 . 8}$ & $1.5+\mathbf{2 8 . 4}$ & $1.3+\mathbf{2 4 . 4}$ & $1.4+\mathbf{2 2 . 8}$ \\
\hline Mirtazapine & 3.2 & $2.6+12.1$ & $2.1+\mathbf{2 0 . 7}$ & $2.0+18.8$ & $2.0+16.3$ \\
\hline Venlafaxine & $2.0+4.4$ & $1.1+10.4$ & $1.3+\mathbf{2 1 . 5}$ & $1.1+18.3$ & $1.2+16.2$ \\
\hline Quetiapine & & 0.7 & $0.3+12.7$ & $1.4+\mathbf{2 8 . 1}$ & $0.6+14.6$ \\
\hline Lamotrigine & & $0.7+\mathbf{2 . 9}$ & $0.1+17.7$ & $0.4+22.2$ & $0.3+14.4$ \\
\hline Olanzapine & 0.4 & $0.9+9.5$ & $0.7+18$ & $1.1+13.6$ & $0.8+12.7$ \\
\hline Carbamazepine & $2.0+21$ & $1.8+18.7$ & $0.4+10.4$ & $0.2+\mathbf{5 . 5}$ & $0.8+11.4$ \\
\hline Escitalopram & & & $0.7+10.1$ & $1.1+\mathbf{1 4 . 4}$ & $0.6+8.5$ \\
\hline Citalopram & $0.8+4.8$ & $1.3+\mathbf{8 . 1}$ & $0.8+9.8$ & $0.2+7$ & $0.7+7.9$ \\
\hline Risperidone & 1.6 & $0.2+5.9$ & $0.1+7.3$ & $0.2+7.6$ & $0.2+6.5$ \\
\hline Sertraline & 0.4 & $0.9+6.4$ & $0.4+5.1$ & $0.5+\mathbf{4 . 0}$ & $0.5+4.4$ \\
\hline Paroxetine & $0.8+8.5$ & $1.3+5.3$ & $0.1+2.5$ & 2.4 & $0.4+3.7$ \\
\hline Perazine & $0.8+5.6$ & $0.4+\mathbf{5 . 3}$ & 3.1 & 1.3 & $0.2+3.2$ \\
\hline Reboxetine & & $1.1+\mathbf{2 . 9}$ & $0.1+4.2$ & $0.2+\mathbf{3 . 0}$ & $0.4+\mathbf{3 . 0}$ \\
\hline Haloperidol & $0.8+11.3$ & $0.4+4.0$ & 1.5 & $0.7+1.3$ & $0.4+3.0$ \\
\hline Duloxetine & & & $0.1+\mathbf{1 . 5}$ & $0.1+6.6$ & $0.1+\mathbf{2 . 9}$ \\
\hline Melperone & 2.0 & $0.2+3.3$ & $0.4+\mathbf{3 . 7}$ & 2.4 & $0.2+\mathbf{2 . 9}$ \\
\hline Promethazine & $0.8+5.6$ & $0.2+3.1$ & $0.1+1.4$ & $0.5+1.7$ & $0.4+2.3$ \\
\hline Aripiprazole & & & 1.5 & $0.1+4.7$ & 2.0 \\
\hline Clozapine & 3.2 & $0.2+\mathbf{2 . 2}$ & $0.3+1.7$ & $0.1+\mathbf{1 . 8}$ & $0.2+\mathbf{2 . 0}$ \\
\hline Fluoxetine & $0.8+1.6$ & 2.6 & $0.4+\mathbf{1 . 5}$ & $0.2+\mathbf{0 . 8}$ & $0.3+1.5$ \\
\hline
\end{tabular}

Table 2: Monotherapy (small numbers) and combination therapy (fat numbers) in percent (\%) of all patients per time period. The substances are listed according to their frequency of prescription, with the most often prescribed substance listed first. Substances with overall prescription rates below $1.5 \%$ are not presented. Year of licensing in the respective countries: lamotrigine: epilepsy 1994, long term bipolar depression 2003; olanzapine: schizophrenia 1996, long term mania 2003; quetiapine: schizophrenia 2000, mania 2004, bipolar depression 2009. 
Interestingly, aripiprazole $(10.0 \%)$ is prescribed more often than olanzapine (9.1\%). The group of SSRI is prescribed in $30.9 \%$.

\section{Frequent combinations of psychotropic substances}

Table $3 \mathrm{a}$ and $\mathrm{b}$ gives the most frequent combinations of at least two or three psychotropic substances in the time period from 1994 to 2009 . The results show, that frequent combinations include lithium, SSRI, mirtazapine, venlafaxine, valproic acid, lamotrigine, quetiapine and olanzapine. Both, lithium and valproic acid are often combined with SSRI, but also with mirtazapine and venlafaxine. Particular combinations with risperidone are

Table 3 a and $\mathbf{b}$ Most frequent combinations of at least two and three substances

\begin{tabular}{|c|c|c|c|}
\hline a. & & & \\
\hline Lithium & SSRI & $9.2 \%$ & \\
\hline Valproic acid & SSRI & 7.2 & \\
\hline Lithium & Mirtazapine & 5.8 & \\
\hline Lithium & Venlafaxine & 5.7 & \\
\hline Quetiapine & SSRI & 5.2 & \\
\hline Quetiapine & Lithium & 5.1 & \\
\hline Lamotrigine & SSRI & 4.9 & \\
\hline Valproic acid & Venlafaxine & 4.6 & \\
\hline Valproic acid & Mirtazapine & 4.5 & \\
\hline Valproic acid & Lithium & 4.1 & \\
\hline Quetiapine & Lamotrigine & 3.9 & \\
\hline SSRI & Mirtazapine & 3.8 & \\
\hline Olanzapine & Lithium & 3.7 & \\
\hline Lamotrigine & Venlafaxine & 3.7 & \\
\hline Olanzapine & SSRI & 3.6 & \\
\hline Quetiapine & Valproic acid & 3.4 & \\
\hline Mirtazapine & Venlafaxine & 3.4 & \\
\hline Lamotrigine & Lithium & 3.3 & \\
\hline Valproic acid & Olanzapine & 3.2 & \\
\hline Lamotrigine & Mirtazapine & 3.2 & \\
\hline b. & & & \\
\hline SSRI & Quetiapine & Lithium & $1.7 \%$ \\
\hline SSRI & Quetiapine & Lamotrigine & 1.3 \\
\hline SSRI & Mirtazapine & Lithium & 1.2 \\
\hline SSRI & Mirtazapine & Valproic acid & 1.2 \\
\hline SSRI & Mirtazapine & Venlafaxine & 1.2 \\
\hline Lithium & Mirtazapine & Venlafaxine & 1.2 \\
\hline SSRI & Olanzapine & Lithium & 1.1 \\
\hline Lithium & Quetiapine & Venlafaxine & 1.1 \\
\hline Lithium & Quetiapine & Lamotrigine & 1.1 \\
\hline
\end{tabular}

Table $3 a$ and $b$ : Most frequent combinations ( $>3 \%$ and $>1 \%$, respectively) of at least two substances (Table $3 \mathrm{a}$ ) and three substances (Table $3 \mathrm{~b}$ ) in percent (\%) of all patients with bipolar depression (1994-2009). not frequent $(<3 \%)$ and hence not included in the table. Combinations with bupropion, fluoxetine, fluvoxamine or paroxetine are very rare and therefore not presented.

\section{Frequent combinations of classes of substances}

Table 4 shows a summary of the most frequent combinations of classes of psychotropic drugs in the treatment of bipolar depression. Most combinations include antidepressants, mainly SSRI. Interestingly, also combinations of two and more antidepressant drugs occur, e.g. SSRI plus mirtazapine plus venlafaxine.

\section{Discussion}

The present study focuses on the psychopharmacological combination treatment of bipolar depression in hospitalized patients in the time period 1994-2009. It shows that lithium given in about one third of the patients is the most frequently administered single substance given at all and concomitantly with other psychotropic drugs. This is also found for the time period 2006-2009, even though the trend to prescribe lithium has decreased over the last 15 years [9]. The data, however, do not allow a specification whether lithium is given due to its antidepressant property, as an augmentation strategy or for preventive purpose.

Clinical studies on the efficacy of lithium show a modest antidepressant effect of lithium in bipolar depression, at best [10-13]. Nevertheless, several guidelines include lithium as a fist-line treatment option alone $[4,6]$ or in combination with other substances, e.g. lamotrigine [2]. The combinations of lithium with other psychotropic drugs found in the present data only include substances that do not interfere with the pharmacokinetics of lithium. Only the risk of serotonergic syndrome may be increased in combinations of lithium with SSRI and / or venlafaxine.

Table 4 Most frequent combinations of classes of psychotropic drugs

\begin{tabular}{lllr}
\hline Lithium & $\begin{array}{l}\text { Antidepressants } \\
\text { (SSRI, Mir, Ven) }\end{array}$ & $\begin{array}{l}\text { atypical Neuroleptics } \\
\text { (Quet, Ola, Ri) }\end{array}$ & $\mathbf{4 \%}$ \\
\hline Lithium & $\begin{array}{l}\text { Antidepressants } \\
\text { (SSRI, Mir, Ven) }\end{array}$ & $\begin{array}{l}\text { Antidepressants } \\
\text { (SSRI, Mir, Ven) }\end{array}$ & $\mathbf{3 \%}$ \\
\hline Lithium & $\begin{array}{l}\text { atypical Neuroleptics } \\
\text { (Quet, Ola, Ri) }\end{array}$ & $\begin{array}{l}\text { Anticonvulsives } \\
\text { (Val, Lam) }\end{array}$ & $\mathbf{1 \%}$ \\
\hline SSRI & $\begin{array}{l}\text { atypical Neuroleptics } \\
\text { (Quet, Ola, Ri) }\end{array}$ & $\begin{array}{l}\text { Anticonvulsives } \\
\text { (Val, Lam) }\end{array}$ & $\mathbf{3 \%}$ \\
\hline SSRI & Mirtazapine & Anticonvulsives & $\mathbf{2 \%}$ \\
\hline SSRI & Mirtazapine & Venlafaxine & $\mathbf{1 \%}$ \\
\hline
\end{tabular}

Table: 4 Classes of psychotropic drugs in the treatment of bipolar depression (1994-2009). Mir: mirtazapine, Ven: venlafaxine, Quet: quetiapine, Ola: olanzapine, Ri: risperidone, Val: valproic acid, Lam: lamotrigine. 
The data also emphasize, that antidepressants are the most frequently prescribed class of drugs given in combination, although the use of antidepressants in bipolar depression is controversial. Since 2002, in US guidelines it is generally recommended to avoid antidepressants in bipolar depression [14]. Especially for mirtazapine and venlafaxine, both found in the present study to be combined often with lithium and valproic acid respectively, there is no data that supports the efficacy of these combinations.

In 2002, international [15] and US guidelines [14] proposed the combination of a non-tricyclic antidepressant (SSRI or bupropion) with mood stabilizer (lithium or lamotrigine) as a treatment option. In accordance with these recommendations and with modern guidelines, that in bipolar depression antidepressants should be prescribed in combination with mood stabilizing and antimanic drugs only we observed that antidepressants are combined mainly with lithium, valproic acid, quetiapine and lamotrigine. However, the evidence based combination recommended by the guidelines, olanzapine plus fluoxetine (OFC), was found to be prescribed only in very few patients (cf. [9]). Bupropion, listed in international guidelines as an antidepressant specifically recommended for bipolar depression, is administered very rarely. Moreover, antidepressants with a high potential for pharmacokinetic interactions, i.e. paroxetine, fluoxetine and fluvoxamine, are not used within the usual combinations. Hence, critical drug-drug interactions are avoided despite increasing polypharmacy (cf. [16]). A trend to polypharmacy has already been described in the treatment of bipolar disorder generally [17-19], a systematic description of this trend for the treatment of bipolar depression is - to our knowledge - given for the first time in our previous [9] and present analysis.

Within the time period of 2006 - 2009, the anticonvulsants valproic acid and lamotrigine were the third and fourth most frequently given substances for bipolar depression and more than every fifth patient receives valproic acid or lamotrigine in combination with other drugs. The efficacy of valproic acid has been validated in clinical studies and recent meta-analyses [20], whereby the efficacy of lamotrigine is still a controversial issue and only a modest antidepressant effect can be expected [21]. In 2004, an international consensus group on Bipolar I Depression Treatment Guidelines recommended lamotrigine with category 1 evidence [22].

Quetiapine was found in the present study to be the second most frequently prescribed substance for bipolar depression during the period from 2006 to 2009, whereby the number of prescriptions has increased rapidly in the last ten years [9]. In 2010, quetiapine was even the most often prescribed single substance, followed by valproic acid and lithium. Evidence for the efficacy of quetiapine in the treatment of bipolar depression is ample [13,23-26]. Therefore, all international guidelines explicitly recommend quetiapine as first line treatment, usually proposed as monotherapy [1-6]. Already in 2005, in the Texas algorithms for treatment of bipolar I depression quetiapine was proposed besides lamotrigine and olanzapine / fluoxetine combination [27] and in 2007, quetiapine was recommended as first line treatment option by the international CANMAT guidelines [28]. However, monotherapy of quetiapine is very unusual in our data and quetiapine was found to be combined frequently with SSRI and mood stabilizers (lithium, valproic acid or lamotrigine). Note that aripiprazole was prescribed in 2010 in $10 \%$ of the patients despite negative trials for bipolar depression [6].

The present study bears some limitations, a detailed description of which is given in Greil et al. 2012 [9]. Most importantly, the study is based on data from hospitalized patients, which suffer from severe depression usually and may be treatment resistant as well. Thus, this population may need a higher number of psychotropic drugs concomitantly as compared to out-patients. Moreover, polypharmacy in our population may be overestimated due to tapering off ineffective drugs and starting new medications.

Overall, the study shows, that multiple combinations of psychotropic substances for therapy of bipolar depression are daily clinical routine. Combinations of antidepressants (SSRI, mirtazapine, venlafaxine) with mood stabilizers (lithium, valproic acid, lamotrigine) and/or atypical neuroleptics (quetiapine, olanzapine, risperidone) are common and combinations of more than one antidepressant substance occur quite often.

The efficacy of these frequent combinations applied has not yet been investigated thoroughly. There is a general agreement, that mood stabilizers (lithium, valpoic acid, lamotrigine) combined with atypical neuroleptics may be efficacious in acute bipolar depression [29-32]. In contrast, the efficacy of combinations with antidepressants, especially with mirtazapine and venlafaxine and the efficacy of combinations involving multiple antidepressant substances are not supported by research data. No studies on the efficacy of mirtazapine for bipolar disorder exist. Concerning venlafaxine, its efficacy in the treatment of bipolar II depression has been shown in small sample sizes only [33-35] and one study shows that venlafaxine may trigger switches to mania [36]. Recent reviews and studies on the efficacy of antidepressants alone or in combination in the treatment of bipolar depression do not find stable effects for their efficacy [37-42]. Indicating awareness of drug safety, combinations with substances that have high interaction properties such as paroxetine, fluoxetine and fluvoxamine were found to be scarce in our data. 


\section{Conclusion}

The present study shows that administration of combinations of psychotropic drugs is an every day phenomenon in clinical routine, although profound knowledge about their efficacy is missing. Corresponding recommendations in international guidelines based on clinical trials on the treatment of bipolar depression would constitute great assistance for physicians, but they are not yet available.

\section{Competing interests}

The authors declare that they have no competing interests. The AMSP Drug Safety Program is organized by the non-profit associations, German, Austrian and Swiss Society of Drug Safety in Psychiatry. Almost all pharmaceutical companies involved in CNS research contribute financial support to the three associations, but they have no influence on the publication.

Educational and research grants since 1993:

Austrian Companies: AstraZeneca Österreich GmbH, Boehringer Ingelheim Austria, Bristol Myers Squibb GmbH, CSC Pharmaceuticals GmbH, Eli Lilly $\mathrm{GmbH}$, Germania Pharma GmbH, GlaxoSmithKline Pharma GmbH, JanssenCilag Pharma $\mathrm{GmbH}$, Lundbeck $\mathrm{GmbH}$, Novartis Pharma GmbH, Pfizer Med Inform, Wyeth Lederle Pharma $\mathrm{GmbH}$.

German Companies: Abbott GmbH \& Co. KG, AstraZeneca GmbH, Aventis Pharma Deutschland GmbH, Bayer Vital GmbH \& Co. KG, Boehringer Mannheim $\mathrm{GmbH}$, Bristol-Myers-Squibb, Ciba Geigy GmbH, Desitin Arzneimittel $\mathrm{GmbH}$, Duphar Pharma GmbH \& Co. KG, Eisai GmbH, esparma GmbH Arzneimittel, GlaxoSmithKline Pharma GmbH \& Co. KG, Hoffmann-La Roche AG Medical Affairs, Janssen-Cilag GmbH, Janssen Research Foundation, Knoll Deutschland $\mathrm{GmbH}$, Lilly Deutschland $\mathrm{GmbH}$ Niederlassung Bad Homburg, Lundbeck GmbH \& Co. KG, Novartis Pharma $\mathrm{GmbH}$, Nordmark Arzneimittel GmbH, Organon GmbH, Otsuka-Pharma Frankfurt, Pfizer GmbH, Pharmacia \& Upjohn GmbH, Promonta Lundbeck Arzneimittel, Rhone-Poulenc Rohrer Gmbh, Sanofi-Synthelabo GmbH, SanofiAventis Deutschland, Schering AG, SmithKline Beecham Pharma GmbH, Solvay Arzneimittel $\mathrm{GmbH}$, Synthelabo, Arzneimittel GmbH, Dr. Wilmar Schwabe $\mathrm{GmbH}$ \& Co., Thiemann Arzneimittel GmbH, Troponwerke GmbH \& Co. KG, Upjohn GmbH, Wander Pharma GmbH, Wyeth-Pharma GmbH. Swiss Companies: AHP (Schweiz) AG, AstraZeneca AG, Bristol-Myers, Squibb AG, Desitin Pharma GmbH, Eli Lilly (Suisse) S.A., Essex Chemie AG, GlaxoSmithKline AG, Janssen-Cilag AG, Lundbeck (Suisse) AG, Mepha Pharma AG, Organon AG, Pfizer AG, Pharmacia, Sanofi-Aventis (Suisse) S.A., SanofiSynthélabo SA, Servier SA, SmithKlineBeecham AG, Solvay Pharma AG, Wyeth AHP (Suisse) AG, Wyeth Pharmaceuticals AG.

\section{Authors' contributions}

AH drew the data out of the AMSP data pool, designed and performed the statistical analysis and was drafting the various versions of the manuscript. WG initiated the study, was planning the conception and revised the final version of the manuscript. SR performed another analysis of a corresponding data set thereby validating the results and provided advice for the final version of the manuscript. RG is the project coordinator of AMSP and was counselling the interpretation of the data. All authors read and approved the final manuscript.

\section{Acknowledgement}

The authors thank all hospitals and staff participating in the AMSP project for their contribution to data collection. For collecting the relevant literature and maintaining the literature data base we appreciate the thorough work of Christel Apfelbaum.

\section{Author details}

${ }^{1}$ Department of Psychiatry, Ludwig Maximilian University, Munich, Germany, Nussbaumstr. 7, Munich 80336, Germany. ${ }^{2}$ Sanatorium Kilchberg, Alte Landstrasse 70, Kilchberg-Zurich 8802, Switzerland. ${ }^{3}$ Department of Clinical Pharmacology and Toxicology, University Hospital Zurich, Raemistrasse 100, Zurich 8091, Switzerland.
Received: 30 April 2012 Accepted: 17 September 2012

Published: 21 September 2012

\section{References}

1. Malhi GS, Adams D, Lampe L, Paton M, O'Connor N, Newton LA, Walter G, Taylor A, Porter R, Mulder RT, et al: Clinical practice recommendations for bipolar disorder. Acta Psychiatr Scand Suppl 2009, 439:27-46.

2. Grunze H, Vieta E, Goodwin GM, Bowden C, Licht RW, Moller HJ, Kasper S: The world federation of societies of biological psychiatry (WFSBP) Guidelines for the biological treatment of bipolar disorders: update 2010 on the treatment of acute bipolar depression. World J Biol Psychiatry 2010, 11:81-109.

3. NICE: Review of Clinical Guidelines (CG38) - Bipolar; the management of bipolar disorder in adults, children and adolescents, in primary and secondary care. National Institute for Health and Clinical Excellence, centre for Clinical Practice 2012, http://publications.nice.org.uk/bipolar-disorder-cg38.

4. Goodwin GM: Evidence-based guidelines for treating bipolar disorder: revised second edition-recommendations from the British Association for Psychopharmacology. J Psychopharmacol 2009, 23:346-388.

5. Kasper S: International Consensus Group on the evidence-based pharmacologic treatment of bipolar I and II depression. J Clin Psychiatry 2008, 69:1632-1646.

6. Yatham LN, Kennedy SH, Schaffer A, Parikh SV, Beaulieu S, O'Donovan C, MacQueen G, McIntyre RS, Sharma V, Ravindran A, et al: Canadian network for mood and anxiety treatments (CANMAT) and international society for bipolar disorders (ISBD) collaborative update of CANMAT guidelines for the management of patients with bipolar disorder: update 2009. Bipolar Disord 2009, 11:225-255

7. Grohmann R, Engel RR, Ruther E, Hippius H: The AMSP drug safety program: methods and global results. Pharmacopsychiatry 2004, 37(Suppl 1):S4-S11.

8. Engel RR, Grohmann R, Ruther E, Hippius $\mathrm{H}$ : Research methods in drug surveillance. Pharmacopsychiatry 2004, 37(Suppl 1):S12-S15.

9. Greil W, Haberle A, Haueis P, Grohmann R, Russmann S: Pharmacotherapeutic trends in 2231 psychiatric inpatients with bipolar depression from the International AMSP Project between 1994 and 2009. J Affect Disord 2012, 136:534-542.

10. Amsterdam JD, Shults J: Comparison of short-term venlafaxine versus lithium monotherapy for bipolar II major depressive episode: a randomized open-label study. J Clin Psychopharmacol 2008, 28:171-181.

11. Suppes T, Marangell LB, Bernstein IH, Kelly DI, Fischer EG, Zboyan HA, Snow $D E$, Martinez M, Al JR, Shivakumar G, et al: A single blind comparison of lithium and lamotrigine for the treatment of bipolar II depression. J Affect Disord 2008, 111:334-343.

12. van der Loos ML, Mulder PG, Hartong EG, Blom MB, Vergouwen AC, de Keyzer HJ, Notten PJ, Luteijn ML, Timmermans MA, Vieta E, et al: Efficacy and safety of lamotrigine as add-on treatment to lithium in bipolar depression: a multicenter, double-blind, placebo-controlled trial. J Clin Psychiatry 2009, 70:223-231.

13. Young AH, McElroy SL, Bauer M, Philips N, Chang W, Olausson B, Paulsson B, Brecher M: A double-blind, placebo-controlled study of quetiapine and lithium monotherapy in adults in the acute phase of bipolar depression (EMBOLDEN I). J Clin Psychiatry 2010, 71:150-162.

14. American Psychiatric Association: Practice guideline for the treatment of patients with bipolar disorder (revision). Am J Psychiatry 2002, 159:1-50.

15. Grunze H, Kasper S, Goodwin G, Bowden C, Baldwin D, Licht R, Vieta E, Moller HJ: World federation of societies of biological psychiatry (WFSBP) guidelines for biological treatment of bipolar disorders. Part I: Treatment of bipolar depression. World J Biol Psychiatry 2002, 3:115-124.

16. Haueis P, Greil W, Huber M, Grohmann R, Kullak-Ublick GA, Russmann S: Evaluation of drug interactions in a large sample of psychiatric inpatients: a data interface for mass analysis with clinical decision support software. Clin Pharmacol Ther 2011, 90:588-596.

17. Frye MA, Ketter TA, Leverich GS, Huggins T, Lantz C, Denicoff KD, Post RM: The increasing use of polypharmacotherapy for refractory mood disorders: 22 years of study. J Clin Psychiatry 2000, 61:9-15.

18. Goldberg JF, Brooks JO III, Kurita K, Hoblyn JC, Ghaemi SN, Perlis RH, Miklowitz DJ, Ketter TA, Sachs GS, Thase ME: Depressive illness burden associated with complex polypharmacy in patients with bipolar disorder: findings from the STEP-BD. J Clin Psychiatry 2009, 70:155-162. 
19. Brooks JO III, Goldberg JF, Ketter TA, Miklowitz DJ, Calabrese JR, Bowden CL, Thase ME: afety and tolerability associated with second-generation antipsychotic polytherapy in bipolar disorder: findings from the Systematic Treatment Enhancement Program for Bipolar Disorder. J Clin Psychiatry 2011, 72:240-247.

20. Smith LA, Cornelius VR, Azorin JM, Perugi G, Vieta E, Young AH, Bowden CL: Valproate for the treatment of acute bipolar depression: systematic review and meta-analysis. J Affect Disord 2010, 122:1-9.

21. Calabrese JR, Huffman RF, White RL, Edwards S, Thompson TR, Ascher JA, Monaghan ET, Leadbetter RA: Lamotrigine in the acute treatment of bipolar depression: results of five double-blind, placebo-controlled clinical trials. Bipolar Disord 2008, 10:323-333.

22. Calabrese JR, Kasper S, Johnson G, Tajima O, Vieta E, Yatham LN, Young AH: International consensus group on bipolar I depression treatment guidelines. J Clin Psychiatry 2004, 65:571-579.

23. Calabrese JR, Keck PE Jr, Macfadden W, Minkwitz M, Ketter TA, Weisler RH, Cutler AJ, McCoy R, Wilson E, Mullen J: A randomized, double-blind, placebo-controlled trial of quetiapine in the treatment of bipolar I or II depression. Am J Psychiatry 2005, 162:1351-1360.

24. Thase ME, Macfadden W, Weisler RH, Chang W, Paulsson B, Khan A, Calabrese JR: Efficacy of quetiapine monotherapy in bipolar I and II depression: a double-blind, placebo-controlled study (the BOLDER II study). J Clin Psychopharmacol 2006, 26:600-609.

25. McElroy SL, Weisler RH, Chang W, Olausson B, Paulsson B, Brecher M, Agambaram V, Merideth C, Nordenhem A, Young AH: A double-blind, placebo-controlled study of quetiapine and paroxetine as monotherapy in adults with bipolar depression (EMBOLDEN II). J Clin Psychiatry 2010, 71:163-174.

26. Suppes T: Effectiveness of the extended release formulation of quetipaine as monotherapy for the treatment of acute bipolar depression. J Affect Disord 2010, 121:106-115.

27. Suppes T, Dennehy EB, Hirschfeld RM, Altshuler LL, Bowden CL, Calabrese JR, Crismon ML, Ketter TA, Sachs GS, Swann AC: The Texas implementation of medication algorithms: update to the algorithms for treatment of bipolar I disorder. J Clin Psychiatry 2005, 66:870-886.

28. Yatham LN, Kennedy SH, O'Donovan C, Parikh SV, MacQueen G, Mclntyre RS, Sharma V, Beaulieu S: Canadian network for mood and anxiety treatments (CANMAT) guidelines for the management of patients with bipolar disorder: update 2007. Bipolar Disord 2006, 8:721-739.

29. Fountoulakis KN, Grunze H, Panagiotidis P, Kaprinis G: Treatment of bipolar depression: an update. J Affect Disord 2008, 109:21-34

30. Baldessarini RJ, Vieta E, Calabrese JR, Tohen M, Bowden CL: Bipolar depression: overview and commentary. Harv Rev Psychiatry 2010, 18:143-157.

31. Ittasakul P, Johnson KR, Srivastava S, Childers ME, Brooks JO III, Hoblyn JC, Ketter TA: Effectiveness of quetiapine plus lamotrigine maintenance therapy in challenging bipolar disorder patients. J Affect Disord 2012, 137:139-145.

32. Chiesa A, Chierzi F, De RD, Serretti A: Quetiapine for bipolar depression: a systematic review and meta-analysis. Int Clin Psychopharmacol 2012, 27:76-90.

33. Amsterdam JD, Wang CH, Shwarz M, Shults J: Venlafaxine versus lithium monotherapy of rapid and non-rapid cycling patients with bipolar II major depressive episode: a randomized, parallel group, open-label trial. $J$ Affect Disord 2009, 112:219-230

34. Amsterdam JD, Shults J: Efficacy and safety of long-term fluoxetine versus lithium monotherapy of bipolar II disorder: a randomized, double-blind, placebo-substitution study. Am J Psychiatry 2010, 167:792-800.

35. Amsterdam JD, Wang G, Shults J: Venlafaxine monotherapy in bipolar type II depressed patients unresponsive to prior lithium monotherapy. Acta Psychiatr Scand 2010, 121:201-208.

36. Leverich GS, Altshuler LL, Frye MA, Suppes T, McElroy SL, Keck PE Jr, Kupka RW, Denicoff KD, Nolen WA, Grunze H, et al: Risk of switch in mood polarity to hypomania or mania in patients with bipolar depression during acute and continuation trials of venlafaxine, sertraline, and bupropion as adjuncts to mood stabilizers. Am J Psychiatry 2006, 163:232-239.

37. Altshuler L, Suppes T, Black D, Nolen WA, Keck PE Jr, Frye MA, McElroy S, Kupka R, Grunze H, Walden J, et al: Impact of antidepressant discontinuation after acute bipolar depression remission on rates of depressive relapse at 1-year follow-up. Am J Psychiatry 2003, 160:1252-1262.

38. Sachs GS, Nierenberg AA, Calabrese JR, Marangell LB, Wisniewski SR, Gyulai $L$, Friedman ES, Bowden CL, Fossey MD, Ostacher MJ, et al: Effectiveness of adjunctive antidepressant treatment for bipolar depression. N Engl J Med 2007, 356:1711-1722.

39. Salvi V, Fagiolini A, Swartz HA, Maina G, Frank E: The use of antidepressants in bipolar disorder. J Clin Psychiatry 2008, 69:1307-1318.

40. Sidor MM, MacQueen GM: Antidepressants for the acute treatment of bipolar depression: a systematic review and meta-analysis. J Clin Psychiatry 2011, 72:156-167.

41. Amit BH, Weizman A: Antidepressant treatment for acute bipolar depression: an update. Depress Res Treat 2012, :684725.

42. Ghaemi SN: Antidepressants in bipolar depression: The clinical debate. Aust.N.Z.J Psychiatry 2012, 46:289-301.

doi:10.1186/1471-244X-12-153

Cite this article as: Haeberle et al:: Mono- and combination drug therapies in hospitalized patients with bipolar depression. Data from the European drug surveillance program AMSP. BMC Psychiatry 2012 $12: 153$.

\section{Submit your next manuscript to BioMed Central and take full advantage of:}

- Convenient online submission

- Thorough peer review

- No space constraints or color figure charges

- Immediate publication on acceptance

- Inclusion in PubMed, CAS, Scopus and Google Scholar

- Research which is freely available for redistribution 